\section{In Vitro Antimicrobial Effect of Cetylpyridinium Chloride on Complex Multispecies Subgingival Biofilm}

Stela Lima Farias de Miranda ${ }^{1} \mathbb{D}$, Jennifer Toledo Damaceno ${ }^{1} \mathbb{B}^{\mathbb{B}}$, Marcelo Faveri $^{1}$ (D), Luciene Cristina Figueiredo ${ }^{1}$ (D), Geisla Mary Silva Soares ${ }^{1}$ (D), Magda Feres ${ }^{1}$ (D), Bruno Bueno-Silva ${ }^{1}$ (D)
'Dental Research Division, UNG Universidade Guarulhos, Guarulhos, SP, Brazil

Correspondence: Bruno BuenoSilva, Praça Teresa Cristina, 229, 07023-070, Guarulhos, SP, Brasil. Tel.: +55-11-2464-1684. e-mail: Bruno.silva@prof.ung.br

\begin{abstract}
Periodontopathogenic subgingival biofilm is the main etiological agent of periodontitis. Thus, a search for antimicrobials as adjuvant for periodontal treatment in the literature is intense. Cetylpyridinium chloride (CPC) is a well-known antimicrobial agent commonly used in mouthrinses. However, CPC effects on a complex biofilm model were not found over the literature. Therefore, the aim of this manuscript is to evaluate $0.075 \%$ CPC antimicrobial properties in a multispecies subgingival biofilm model in vitro. The subgingival biofilm composed by 31 species related to periodontitis was formed for 7 days, using the calgary device. The treatments with CPC and chlorhexidine (CHX) 0.12\% (as positive control) were performed 2x/day, for $1 \mathrm{~min}$, from day 3 until the end of experimental period, totaling 8 treatments. After 7 days of biofilm formation, biofilm metabolic activity was evaluated by a colorimetric reaction and biofilms microbial composition by DNA-DNA hybridization. Statistical analysis was performed using ANOVA with data transformed via BOX-COX followed by Dunnett post-hoc. Both CPC and CHX reduced biofilm metabolic activity in $60 \%$ and presented antimicrobial activity against 13 different species. Specifically, only CHX reduced levels of F.n. vicentii and $P$. gingivalis while only CPC reduced $A$. odontolyticus and $A$. israelli. CPC was as effective as $\mathrm{CHX}$ as antimicrobial through in vitro complex multispecies subgingival biofilm. However, future studies using in vivo models of experimental periodontal disease should be performed to prove such effect.
\end{abstract}

Key Words: biofilms, cetylpyridinium, chlorhexidine, mouthwashes

\section{Introduction}

Periodontal diseases are mixed infections caused by bacterial species organized into a dysbiotic biofilm that colonize dental surfaces and induces a host inflammatory response, leading to destruction of tooth supporting tissues and consequently, tooth loss. The main etiological factor of periodontitis is the subgingival biofilm (1). A classical manuscript of Socransky (2) identified the microbiota found over thousands of periodontal patients and organized the microorganisms into five complexes, according to health or disease.

In this way, several antimicrobials have been tested to control subgingival biofilm and chlorhexidine (CHX) is considered the gold agent to control biofilms in oral cavity. However, it is also known that when used for a prolonged period, chlorhexidine may produce side effects which limits its use. Teeth and restorations staining, taste loss and oral mucosa burning sensation are the most common chlorhexidine undesirable effects (3).

An option to $\mathrm{CHX}$ commonly used in diary oral products is cetylpyridinium chloride (CPC), a broad-spectrum antimicrobial, considered to have less side effects than $\mathrm{CHX}$. Previously on the literature, the CPC 0.05\% antimicrobial effects on caries-related microorganisms was very clear. CPC mouthrinse was effective against Streptococcus mutans, Actinomyces viscosus and saliva-derived biofilms (4).

In addition, CPC $0.05 \%$ antimicrobial activity on several aerobe and anaerobe microorganisms in planktonic form, including Aggregatibacter actinomycemcomitans, Campylobacter rectus, Eikenella corrodens, Porphyromonas gingivalis, Prevotella intermedia and Solobacterium moorei were demonstrated and minimal inhibitory concentration determined. An ex-vivo supragingival plaque experiment also tested CPC 0.05\% mouthrinse and obtained as result more than $90 \%$ of bacteria killed (5). At last, a clinical study demonstrated CPC 0.05\% efficacy on controlling supragingival dental plaque and gingivitis (6) and a commercial solution with CPC $0.05 \%$ was considered as effective as $\mathrm{CHX} 0.12 \%$ when used as preprocedural mouthrinse to decrease microbial contamination in spatter (7).

Recently, CPC started to be used at $0.075 \%$ and clinical studies demonstrated its efficacy in reduce biofilm formation and gingival inflammation for 6 months without serious clinical side effects $(8,9)$. In addition, CPC 0.075\% also reduced bacteria levels in dental aerosols when used previously to a dental procedure (10). However, no experiments testing CPC on complex subgingival 
biofilms were found over the literature, probably due to the resistance and the high challenge that these kinds of biofilms offer against antimicrobials (11).

A complex multispecies subgingival biofilm model composed of 40 species was proposed (12) as a good option to study the development of the periodontitis main etiological factor. The establishment of in vitro biofilm models that mimic biofilms in vivo is a major challenge for scientists. Although many advances have been achieved in studies with individual species, the understanding of the behavior of multiple species coexisting in an environment is essential for the establishment of strategies for prevention, diagnosis, treatment and prognosis of infectious processes (11). In this sense, it is believed that this model is one of that best mimics subgingival biofilm formation due to the presence of several different bacterial species, including components of all Socransky complexes. It is known that the subgingival biofilm is quite complex and composed of several bacterial species and thus, literature demonstrates that in vitro model with few species does not adequately mimic what happens in the subgingival environment $(13,14)$. As a limitation, this model does not mimic the

\section{Material and Methods}

Biofilm Formation

The species used to form multispecies biofilm are Actinomyces naes/undiiATCC 12104, Actinomyces oris ATCC 43146, Actinomyces gerencseriae ATCC 23840, Actinomyces israelii ATCC 12102, Veillonella parvula ATCC 10790, Actinomyces odontolyticus ATCC 17929, Streptococcus sanguinis ATCC 10556, Streptococcus oralis ATCC 35037, Streptococcus intermedius ATCC 27335, Streptococcus gordonii ATCC 10558, Streptococcus mitis ATCC 49456, Aggregatibacter actinomycetemcomitans ATCC 29523, Capnocytophaga ochracea ATCC 33596, Capnocytophaga gingivalis ATCC 33624, Eikenella corrodens ATCC 23834, Capnocytophaga sputigena ATCC 33612, Streptococcus constellatus ATCC 27823, Eubacterium nodatum ATCC 33099, Fusobacterium nucleatum vincentii ATCC 49256, Parvimonas micra ATCC 33270, Fusobacterium nucleatum polymorphum ATCC 10953, Campylobacter showae ATCC 51146, Fusobacterium periodonticum ATCC 33693, Prevotella intermedia ATCC 25611, Porphyromonas gingivalis ATCC 33277, Tannerella forsythia ATCC 43037, Eubacterium saburreum ATCC 33271, Streptococcus anginosus ATCC 33397, Selenomonas noxia ATCC 43541, Propionibacterium acnes ATCC 11827 and G. morbillorum

\section{ATCC 27824.}

Most species were grown on tryptone soy agar with 5\% sheep blood under anaerobic conditions (85\% nitrogen, 10\% carbon dioxide, and 5\% hydrogen), except Eubacterium saburreum subsp. that was cultured on fastidious anaerobic agar with 5\% sheep blood. P. gingivalis were grown on tryptone soy agar with yeast extract enriched with $1 \%$ hemin, 5\% menadione and 5\% sheep blood. For T. forsythia the media used contained tryptone soy agar with yeast extract enriched with 1\% hemin, $5 \%$ menadione, $5 \%$ sheep blood, and $1 \% \mathrm{~N}$-acetylmuramic acid. After $24 \mathrm{~h}$ of growth, all species were transferred to tubes with $\mathrm{BHI}$ culture medium (Becton Dickinson, Sparks, MD) supplemented with $1 \%$ hemin.

After $24 \mathrm{~h}$, the optical density (OD) was adjusted to inoculum have about $10^{8} \mathrm{cells} / \mathrm{ml}$ of each species. The individual cell suspensions were diluted and $100 \mu \mathrm{L}$ aliquots containing $10^{6}$ cells from each species were mixed with $11900 \mu \mathrm{L}$ of BHI broth supplemented with $1 \%$ hemin and $5 \%$ sheep blood to give a final $15 \mathrm{ml}$ biofilm inoculum.

Calgary biofilm device, consisting of a 96-well plate (Nunc; Thermo Scientific, Roskilde, Denmark), was used to develop the multiple biofilm species model. A $150 \mu \mathrm{L}$ inoculum aliquot, containing $10^{4}$ cells of each species, was added per well and a plate cover containing polystyrene pins (Nunc TSP system; Thermo Scientific, Roskilde, Denmark). The coated plates were incubated at $37 \mathrm{C}$ under anaerobic conditions. After $72 \mathrm{~h}$ of incubation, plate covers were transferred to fresh 96-well plates with fresh broth (BHI broth supplemented with 1\% hemin and 5\% sheep blood) and kept at $37^{\circ} \mathrm{C}$ under anaerobic conditions until 7 days of biofilm formation (12).

\section{Biofilm Treatments}

Treatments initiated on $72 \mathrm{~h}$-biofilm, being performed twice a day during the next 4 days. Biofilm-coated pins were transferred to 96-well plates containing CPC 0.075\% (Colgate Plax Classic, São Bernardo do Campo, SP, Brazil), CHX 0.12\% (Colgate PerioGard, São Bernardo do Campo, SP, Brazil) and culture medium (for the non-treated biofilmscoated pins), for 1 min each treatment, and then, biofilmcoated pins returned to the original culture medium (16).

\section{Biofilm Metabolic Activity}

The percentage reduction of biofilm metabolic activity was determined using 2,3,5-triphenyltetrazolium chloride (TC) (catalog No. 17779; Fluka analytical) and spectrophotometry. TC is used for differentiation between metabolically active and inactive cells. The white substrate is enzymatically reduced to red formazan 1,3,5-triphenyl (TPHP) by bacterial live cells, due to the activity of several dehydrogenases. The change in substrate color is read by 
spectrophotometry to determine the rate of reduction, which is used as an indirect measure of bacterial metabolic activity. To measure the metabolic activity of biofilms, the pins were transferred to plates with $200 \mu \mathrm{L}$ per well of fresh $\mathrm{BHI}$ medium containing 1\% hemin with $10 \%$ of a $1 \%$ $\Pi \mathrm{C}$ solution. The plates were incubated under anaerobic conditions for $24 \mathrm{~h}$ at $37^{\circ} \mathrm{C}$. The $\Pi \mathrm{C}$ conversion was read at $485 \mathrm{~nm}$ using a spectrophotometer (12).

\section{DNA-DNA Hybridization (Checkerboard DNA-DNA).}

Three 7-day biofilm coated pins of each of the groups was transferred to Eppendorf tubes containing $100 \mu \mathrm{L}$ of TE buffer (10 mM Tris-HCl, 1 mM EDTA [pH 7,6]), and then $100 \mu \mathrm{L}$ of $0.5 \mathrm{M} \mathrm{NaOH}$ were added. The tubes containing the pins and the final solution were boiled for $10 \mathrm{~min}$ and the solution neutralized with the addition of $0.8 \mathrm{~mL}$ of ammonium $5 \mathrm{M}$. The samples were analyzed individually for the presence and quantity of the 31 bacterial species, using DNA-DNA hybridization technique. Briefly, upon lysis of the samples, the DNA was plated onto a nylon membrane using a Minislot device (Immunetics, Cambridge, MA). After DNA attachment to the membrane, it was placed in a Miniblotter 45 (Immunetics). Digoxigenin labeled with DNA probes of the entire genome for the subgingival species used were hybridized to individual lanes of Miniblotter 45. After hybridization, the membranes were washed, and DNA probes were detected using a specific antibody to digoxigenin conjugated to phosphatase alkaline. The signals were detected using AttoPhos substrate (Amersham Life Sciences, Arlington Heights, IL), and the results were obtained using Typhoon Trio Plus (Molecular Dynamics, Sunnyvale, CA). Two lanes in each race contained the standards with $10^{5}$ and $10^{6}$ cells of each species. Signals obtained with the Typhoon Trio were converted to absolute counts, by comparison with the patterns on the same membrane. Failure to detect a signal was recorded as zero. The values obtained after CPC treatments were compared with the values of negative and positive controls (12). Counts below method detection limit $\left(1 \times 10^{4}\right)$ were considered as zero to calculate the mean counts of respective bacterial species.

\section{Statistical Analysis}

Biofilm metabolic results and all checkboard data were submitted to statistical analysis using KruskalWallis analysis followed by Dunnett post-hoc.

\section{Results}

\section{Biofilm Metabolic Activity}

Figure 1 shows the metabolic activity of biofilm treated with CPC $0.075 \%$, CHX $0.12 \%$ and non-treated biofilms. CPC and CHX were able to significantly reduce approximately $60 \%$ of biofilm metabolic activities $(p<0.05)$.

Figure 2 shows $\mathrm{CPC}$ and $\mathrm{CHX}$ reduction effects on total counts of all species included in the biofilm. CPC and CHX significantly reduced approximately 96 and $99 \%$ of bacteria total counts, respectively. CPC and CHX did not differ between each other.

Figure 3 presents results regarding each species analysis, CPC and CHX did not statistically differ for none of the bacteria included in biofilms $(\mathrm{p} \geq 0.05)$. CPC and CHX statistically reduced levels of $S$. oralis, $S$. intermedius, S. gordonii, V. parvula, A. naeslundii, A. gerencisiae, C. gingivalis, E. corrodens, P. micra, S. constelatus, E. saburreum, $P$. acnes and G. morbillorum $(p \leq 0.05)$ when compared to vehicle-treated biofilms. A. odontolyticus and $\mathrm{A}$. israelli were only affected by CPC $(\mathrm{p} \leq 05)$ while $P$. gingivalis and $F$. nucleatum vicentii were only inhibited by $\mathrm{CHX}(\mathrm{p} \leq 0.05)$.

\section{Discussion}

Chlorhexidine is commonly used as adjuvant to

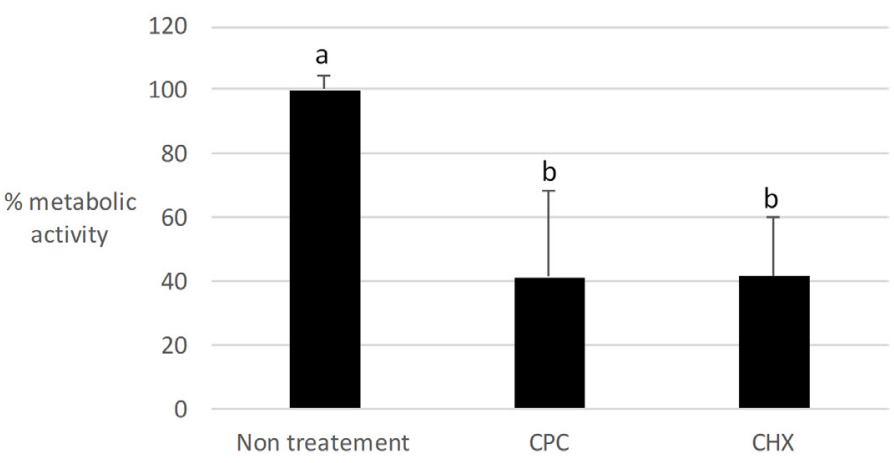

Figure 1. Metabolic activity of biofilms treated with vehicle (negative control), cetylpyridinium chloride (CPC) and chlorhexidine $0.12 \%$. Vehicle results were considered as 100\% of metabolic activity and different letters means statistical significance by Kruskal-Wallis analysis followed by Dunnett post-hoc $(\mathrm{p} \leq 0.05)$

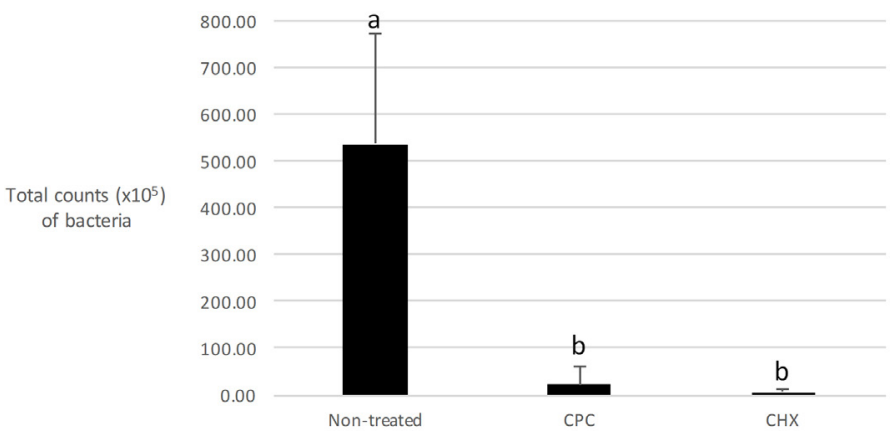

Figure 2. Total counts $\left(\times 10^{5}\right)$ of non-treated biofilm microorganisms and biofilms treated with CPC 0.075\% and CHX 0.12\%. Different letters mean statistical significance by Kruskal-Wallis analysis followed by Dunnett post-hoc $(\mathrm{p} \leq 0.05)$ 
periodontal treatment or indicated to patients that has difficulties to control oral biofilm by themselves. Since early in the seventies, chlorhexidine $0.12 \%$ was considered the gold-standard antimicrobial to control periodontitis biofilms. However its side effects such as teeth staining and others makes dentists and scientists to start over whether chlorhexidine still deserves the gold-standard title $(3,17)$.

Since CPC did not have side effects reported over the literature, it appears as a good option instead of CHX. In this way, CPC has been proposed to be used as mouthwash pre-dental procedure (7), as an adjunct to mechanical periodontal treatment (8), in the treatment of halitosis (18), to control oropharyngeal infections (19) and has anti-cariogenic properties (20).

Herein we demonstrated that CPC $0.07 \%$ and $\mathrm{CHX}$ $0.12 \%$ were statistically equal effective in reducing biofilm metabolic activity, total counts biofilm microorganisms and levels of 13 different species used in our biofilm model. Therefore, cetylpyridinium chloride $0.075 \%$ were as effective as chlorhexidine $0.12 \%$, considered as a gold-standard mouthwash to control oral biofilms (3). To the best of our knowledge, this is the first manuscript to

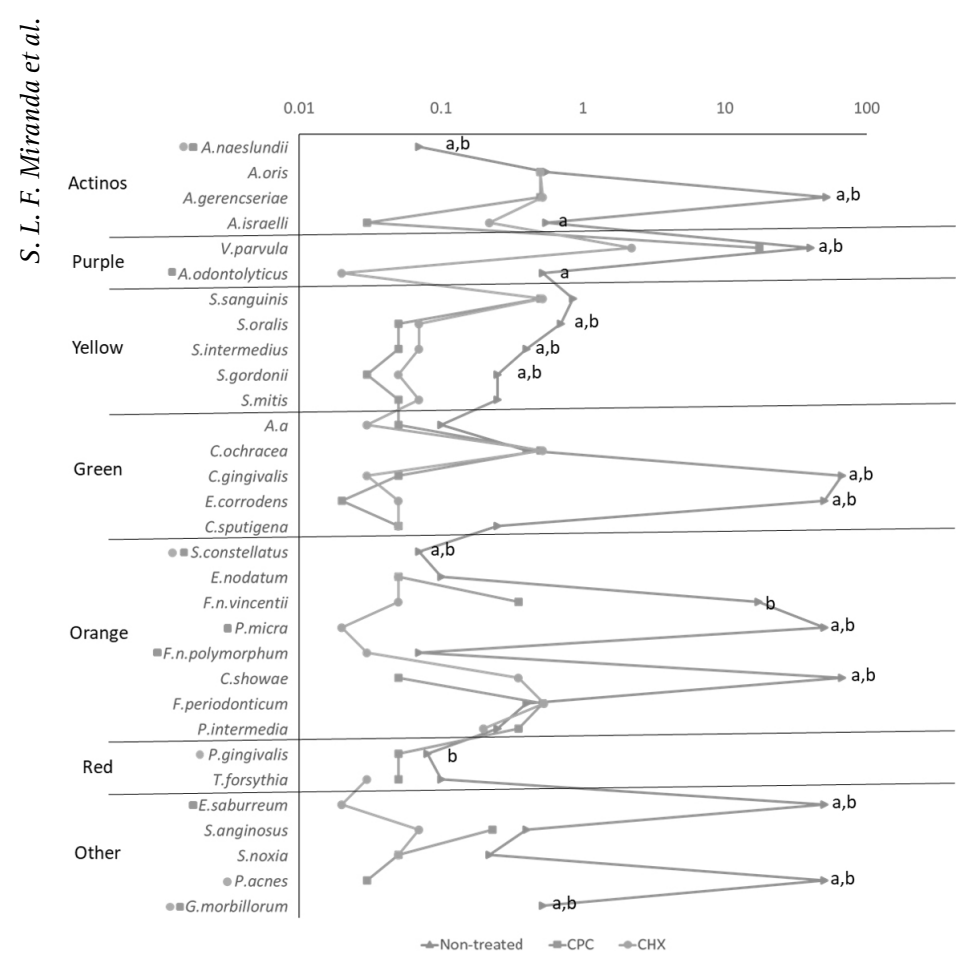

Figure 3. Mean counts $\left(\mathrm{x} 10^{5}\right)$ of bacteria belonging to actinos, yellow, purple, green, orange, red and other complexes, treated with culture media (nontreated), CPC $0.075 \%$ and CHX $0.12 \%$. Species were ordered according to microbial complexes described by Socransky et al., 1998. - at left side of bacteria name means 0 counts of bacteria in biofilm treated with CHX and CPC respectively. Statistical analysis was performed by Analysis of Variance (ANOVA) followed by Dunn test for each bacteria species separately. ${ }^{a}$ means statistical significance between CPC-treated biofilms and non-treated biofilms but no statistical significance between CPC- and CHX-treated biofilms; ${ }^{b}$ means statistical significance between CHX-treated biofilms and non-treated biofilms but no statistical significance Between CHX- and CPC-treated biofilms demonstrated CPC effects in such complex subgingival biofilm model.

CPC and CHX significantly reduced levels of same microorganisms from yellow (S. oralis, S. intermedius and S. gordonii), green (C. gingivalis and E. corrodens) and other (E. saburreum, P. acne and G. morbillorum) complexes. Regarding components of orange complex, both antimicrobials statistically acted on $C$. showae, $P$. micra, S. constelatus and only CHX decreased levels of $\mathrm{F}$. nucleatum vicentii.

S. gordonii levels reduction CPC and CHX treatments is noteworthy. In the last few years, S. gordonii have been consider as an accessory keystone pathogen for periodontitis since this microorganism increase the boneloss provoked by $P$. gingivalis (21).

As a limitation of CPC use, levels of $P$. gingivalis (red complex) was only statistically reduced by $\mathrm{CHX}$. Levels of this periodontopathogen in CPC-treated biofilms were statistical similar to non-treated and CHX-treated biofilms. Nevertheless, it was possible to observe a tendency of reduction of $P$. gingivalis levels and this result is in accordance with the literature (10). Herein, CPC reduced $50 \%$ of $P$. gingivalis levels however, this result was not statistically significant. The same pattern was observed for another member of red complex, T. forsythia. Untreated biofilms present $1 \times 10^{4}$ of $\mathrm{T}$. forsythia cells according to checkerboard analysis while CPC reduced this microorganism levels to $5 \times 10^{3}$ and $\mathrm{CHX}$ to $3.33 \times 10^{3}$. However, this difference was not statistically significant for none of groups.

On the other hand only CPC reduced levels of A. israelli, member of actinos complexe and then, considered as early and "healthy" colonizer (22). Nevertheless, a clinical study demonstrated that $A$. israeli appears to be present in greater amount in patients with generalized aggressive periodontitis than in chronic periodontitis (23). Moreover, A. israelli was more frequently found in chronic periodontitis patients than in healthy subjects, being detected in both shallow and deep pockets (24).

In addition, only CPC reduced levels of $A$. odontolyticus, which role in root caries and canal infections were clearly demonstrated through literature however its role in periodontal disease still deserves more investigation. So far, it is known that this microorganism may be found in shallow and deep pockets and that it has a great adherence and co-aggregration ability. In this way, A. odontolyticus, considered as a bridge for orange complex colonization (24).

Although we used a commercially available product with sodium fluoride (NaF) $0.05 \%$ and $\mathrm{CPC}$ 
$0.075 \%$ as active ingredients, literature demonstrated that sodium fluoride did not influence the antibacterial and anti-biofilm potency of CPC-containing mouthrinses (4). Therefore, the antimicrobial activity observed through our study was exclusively due to CPC and not due to sodium fluoride. A recent review suggests that concentrations higher than $0.05 \%$ of CPC provide significant benefits but still, $\mathrm{CHX}$ results is better in clinical control of dental biofilm formation (25). Moreover, is already known in the literature that mouthrinses have low evidence to promote a long-lasting impact on microbiota from deep periodontal pockets (15) being more effective on supragingival bacteria. Since supragingival biofilm is known to initiate subgingival biofilm formation, results from present manuscript may indicate that CPC may have a beneficial impact during the manutention phase of periodontal treatment by favoring a healthy-associated microbiota recolonization. In addition, results from antibacterial agents on the present model may be interpreted as a preventive action to inhibit biofilm formation once the mode of antibacterial application on periodontal pockets remain an issue to be solved.

In this sense, it is important to keep in mind that the scientific evidence supporting the clinical treatment procedures is based on systematic reviews with metaanalysis and to randomized clinical trials. Hence, results of present manuscript should not support modifications over clinical treatment of periodontitis, but it may provide the basis for future in vivo studies using CPC 0.075\%."

Therefore, within the limitations of an in vitro study, CPC $0.075 \%$ were as effective of CHX $0.12 \%$ through a multispecies complex biofilm model in vitro. Future in vivo studies should evaluate CPC antimicrobial properties as an adjuvant to periodontal disease treatment.

\section{Resumo}

0 biofilme subgengival periodontopatogênico é o principal agente etiológico da periodontite. Assim, a pesquisa de antimicrobianos como adjuvantes para o tratamento periodontal na literatura é intensa. Cloreto de cetilpiridínio (CPC) é um agente antimicrobiano comumente usado em enxaguatórios bucais. No entanto não foram encontrados na literatura estudos avaliando os efeitos do CPC em um modelo complexo de biofilme. Portanto, o objetivo deste artigo é avaliar as propriedades antimicrobianas do cloreto de cetilpiridinio $0,075 \%$ em um modelo de biofilme subgengival multiespécie in vitro. 0 biofilme subgengival composto por 31 espécies relacionadas à periodontite foi formado por 7 dias, utilizando o dispositivo calgary. Os tratamentos com CPC e clorexidina (CHX) 0,12\% (controle positivo) foram realizados $2 x / \mathrm{dia}$, por $1 \mathrm{~min}$, do dia 3 até o final do periodo experimental, totalizando 8 tratamentos. Após 7 dias de formação do biofilme, a atividade metabólica do biofilme foi avaliada por reação colorimétrica e a composição microbiana dos biofilmes por hibridização DNA-DNA. A análise estatística foi realizada usando ANOVA com dados transformados via BOX-COX seguido do teste de Dunnett. Tanto o CPC como a CHX reduziram a atividade metabólica do biofilme em aproximadamente $60 \%$ e apresentaram atividade antimicrobiana contra 13 espécies diferentes. Especificamente, apenas os niveis de F.n. Vicentii e $P$. gingivalis foram reduzidos somente pelo tratamento com a CHX enquanto apenas o CPC reduziu $A$. odontolyticus e $A$. israelli. O CPC foi tão eficaz quanto o CHX como antimicrobiano através de biofilme subgengival complexo multiespecífico in vitro. No entanto, futuros estudos usando modelos in vivo de doença periodontal experimental devem ser realizados para comprovar tal efeito.

\section{Acknowledgements}

The authors thank the Coordination for the Improvement of Higher Education Personnel (CAPES) for the scholarship provided to first author and National Council for Scientific and Technological Development (CNPq) for the scholarship provided to second author.

\section{References}

1. Mira A, Simon-Soro A, Curtis MA. Role of microbial communities in the pathogenesis of periodontal diseases and caries. J Clin Periodontol 2017;44:S23-S38.

2. Socransky SS, Haffajee AD, Dzink JL, Hillman JD. Associations between microbial species in subgingival plaque samples. Oral Microbiol Immunol 1988;31-37.

3. James $P$, Worthington $H V$, Parnell $C$, Harding $M$, Lamont $T$, Cheung $A$, et al. Chlorhexidine mouthrinse as an adjunctive treatment for gingival health. The Cochrane database of systematic reviews 2017;3:CD008676

4. Latimer J, Munday JL, Buzza KM, Forbes S, Sreenivasan PK, McBain AJ. Antibacterial and anti-biofilm activity of mouthrinses containing cetylpyridinium chloride and sodium fluoride. BMC microbiology 2015;15:169.

5. Sreenivasan PK, Haraszthy VI, Zambon JJ. Antimicrobial efficacy of 0.05\% cetylpyridinium chloride mouthrinses. Letters App Microbiol 2013;56:14-20.

6. Silva MF, dos Santos NB, Stewart B, DeVizio W, Proskin HM. A clinical investigation of the efficacy of a commercial mouthrinse containing $0.05 \%$ cetylpyridinium chloride to control established dental plaque and gingivitis. J Clin Dent 2009;20:55-61.

7. Feres M, Figueiredo LC, Faveri M, Stewart B, de Vizio W. The effectiveness of a preprocedural mouthrinse containing cetylpyridinium chloride in reducing bacteria in the dental office. J Amer Dent Assoc 2010;141:415-422.

8. Costa X, Laguna E, Herrera D, Serrano J, Alonso B, Sanz M. Efficacy of a new mouth rinse formulation based on $0.07 \%$ cetylpyridinium chloride in the control of plaque and gingivitis: a 6-month randomized clinical trial. J Clin Periodontol 2013;40:1007-1015.

9. Van Leeuwen MP, Rosema NA, Versteeg PA, Slot DE, Van Winkelhoff AJ, Van der Weijden GA. Long-term efficacy of a $0.07 \%$ cetylpyridinium chloride mouth rinse in relation to plaque and gingivitis: a 6-month randomized, vehicle-controlled clinical trial. Int J Dent Hyg 2015;13:93-103.

10. Retamal-Valdes B, Soares GM, Stewart B, Figueiredo LC, Faveri M, Miller $S$, et al. Effectiveness of a pre-procedural mouthwash in reducing bacteria in dental aerosols: randomized clinical trial. Braz Oral Res 2017;31:e21.

11. Socransky SS, Haffajee AD. Dental biofilms: difficult therapeutic targets. Periodontol 2000 2002;28:12-55.

12. Soares GM, Teles F, Starr JR, Feres M, Patel M, Martin L, et al. Effects of azithromycin, metronidazole, amoxicillin, and metronidazole plus amoxicillin on an in vitro polymicrobial subgingival biofilm model. Antimicrob Agents Chemoth 2015;59:2791-2798.

13. Guggenheim M, Shapiro S, Gmur R, Guggenheim B. Spatial arrangements and associative behavior of species in an in vitro oral biofilm model. App Environ Microbiol 2001;67:1343-1350.

14. Sanchez MC, Llama-Palacios A, Blanc V, Leon R, Herrera D, Sanz M. Structure, viability and bacterial kinetics of an in vitro biofilm model using six bacteria from the subgingival microbiota. J Periodontol Res 2011;46:252-260.

15. Arweiler NB, Auschill TM, Sculean A. Patient self-care of periodontal pocket infections. Periodontol 2000 2018;76:164-179.

16. Miranda SLF, Damasceno JT, Faveri M, Figueiredo L, da Silva HD, 
Alencar SMA, et al. B. Brazilian red propolis reduces orange-complex periodontopathogens growing in multispecies biofilms. Biofouling 2019;35:308-319.

17. Jones CG. Chlorhexidine: is it still the gold standard? Periodontol 2000 1997;15:55-62.

18. Mendes L, Coimbra J, Pereira AL, Resende M, Pinto MG. Comparative effect of a new mouthrinse containing chlorhexidine, triclosan and zinc on volatile sulphur compounds: a randomized, crossover, doubleblind study. Int J Dental Hyg 2016;14:202-208.

19. Pitten FA, Kramer A. Efficacy of cetylpyridinium chloride used as oropharyngeal antiseptic. Arzneimittel-Forschung 2001;51:588-595.

20. Pandit S, Cai JN, Jung JE, Lee YS, Jeon JG. Effect of brief cetylpyridinium chloride treatments during early and mature cariogenic biofilm formation. Oral Dis 2015;21:565-571.

21. Hajishengallis G. Periodontitis: from microbial immune subversion to systemic inflammation. Nat Rev Immunol 2015;15:30-44.

22. Socransky SS, Haffajee AD. Periodontal microbial ecology. Periodontol 2000 2005;38:135-187.

23. Heller D, Silva-Boghossian CM, do Souto RM, Colombo AP. Subgingival microbial profiles of generalized aggressive and chronic periodontal diseases. Arch Oral Biol 2012;57:973-980.

24. Vielkind $P$, Jentsch $H$, Eschrich $K$, Rodloff AC, Stingu CS. Prevalence of Actinomyces spp. in patients with chronic periodontitis. Int J medical microbiology: IJMM 2015;305:682-688.

25. Takenaka S, Ohsumi T, Noiri Y. Evidence-based strategy for dental biofilms: Current evidence of mouthwashes on dental biofilm and gingivitis. Japan Dent Sci Rev 2019;55:33-40.

Received March 29, 2019

Accepted October 21, 2019 